\title{
Anthrax Edema Toxin Modulates PKA- and CREB- Dependent Signaling in Two Phases
}

\author{
Andrea Puhar ${ }^{1 \mathrm{x}_{*}}$, Federica Dal Molin ${ }^{1}$, Stéphanie Horvath ${ }^{1}$, Daniel Ladants ${ }^{2}$, Cesare Montecucco ${ }^{1 *}$ \\ 1 Dipartimento di Scienze Biomediche Sperimentali, Università di Padova, Padova, Italy, 2 Unité de Biochimie des Interactions Macromoléculaires, CNRS URA 2185, Institut \\ Pasteur, Paris, France
}

\begin{abstract}
Background: Anthrax edema toxin (EdTx) is an adenylate cyclase which operates in the perinuclear region of host cells. However, the action of EdTx is poorly understood, especially at molecular level. The ability of EdTx to modulate cAMPdependent signaling was studied in Jurkat T cells and was compared with that of other CAMP-rising agents: Bordetella pertussis adenylate cyclase toxin, cholera toxin and forskolin.

Methodology/Principal Findings: EdTx caused a prolonged increase of the intracellular CAMP concentration. This led to nuclear translocation of the CAMP-dependent protein kinase (PKA) catalytic subunit, phosphorylation of cAMP response element binding protein (CREB) and expression of a reporter gene under control of the CAMP response element. Neither p90 ribosomal S6 kinase nor mitogen- and stress-activated kinase, which mediate CREB phosphorylation during $T$ cell activation, were involved. The duration of phospho-CREB binding to chromatin correlated with the spatio-temporal rise of cAMP levels. Strikingly, EdTx pre-treated T cells were unresponsive to other stimuli involving CREB phosphorylation such as addition of forskolin or $\mathrm{T}$ cell receptor cross-linking.

Conclusions/Significance: We concluded that, in a first intoxication phase, EdTx induces PKA-dependent signaling, which culminates in CREB phosphorylation and activation of gene transcription. Subsequently CREB phosphorylation is impaired and therefore $T$ cells are not able to respond to cues involving CREB. The present data functionally link the perinuclear localization of EdTx to its intoxication mechanism, indicating that this is a specific feature of its intoxication mechanism.
\end{abstract}

Citation: Puhar A, Dal Molin F, Horvath S, Ladants D, Montecucco C (2008) Anthrax Edema Toxin Modulates PKA- and CREB-Dependent Signaling in Two Phases. PLoS ONE 3(10): e3564. doi:10.1371/journal.pone.0003564

Editor: Adam J. Ratner, Columbia University, United States of America

Received July 22, 2008; Accepted September 22, 2008; Published October 29, 2008

Copyright: (c) 2008 Puhar et al. This is an open-access article distributed under the terms of the Creative Commons Attribution License, which permits unrestricted use, distribution, and reproduction in any medium, provided the original author and source are credited.

Funding: This work was supported by grants from the Anthrax-EuroNet, Istituto Superiore della Sanità Italy USA protocol on "Programmi di Ricerca sulle Malattie di Grande Rilievo Sociale-Meccanismi tossinogenici e preparazione di antigeni vaccinali", and Network of Excellence EuroPathoGenomics from the European Commission to C. M., and grants from Institut Pasteur and from the EU 6th Framework Programme Contract LSHB-CT-2004-503582 (Theravac) to D. L.. The funders had no role in study design, data collection and analysis, decision to publish, or preparation of the manuscript.

Competing Interests: The authors have declared that no competing interests exist.

* E-mail: andrea.puhar@pasteur.fr (AP); cesare.montecucco@unipd.it (CM)

a Current address: Unité de Pathogénie Microbienne Moléculaire, INSERM U786, Institut Pasteur, Paris, France

\section{Introduction}

Anthrax is caused by Bacillus anthracis, a Gram-positive, sporulating bacterium. This organism is commonly found in soil and it mainly infects large herbivores, but occasionally also humans. The spores can enter the body from skin abrasions, the gastro-intestinal tract, or the lungs. Whilst cutaneous anthrax has only local effects, the gastro-intestinal and inhalation forms may lead to a systemic infection, causing septicemia and toxemia. Fatality of inhalation anthrax is very high $[1,2]$. Even though $B$. anthracis is sensitive to different antibiotics, their therapeutic benefit is frequently diminished by the late onset of symptoms. Therefore, in recent years much research focused at finding new therapeutics that block the action of anthrax toxins, which are major virulence factors of B. anthracis [3].

Pathogenic strains of $B$. anthracis harbor three plasmid-encoded virulence factors: a polyglutamic capsule and two A-B toxins $[2,4]$. These toxins consist of two enzymatic components, edema factor (EF) and lethal factor (LF) which share their B carrier, termed anthrax protective antigen (PA) [5]. PA can associate with two cell surface receptors, tumor endothelial marker 8 (TEM8) and capillary morphogenesis protein 2 (CMG2) [6,7], and possibly with the co-receptor low-density lipoprotein receptor-related protein LRP6 [8-10]. On to the cell surface, PA forms a heptamer that binds up to three molecules of EF or LF [5]. After endocytosis, at low $\mathrm{pH}$, the heptamer dissociates from the receptors and inserts into the lipid bilayer forming a pore through which partially unfolded EF and LF cross the membrane [11]. The slightly acidic $\mathrm{pH}$ of early endosomes is sufficient to mediate the detachment of toxins from TEM8, but the more acidic $\mathrm{pH}$ of late endosomes (LEs) is required for their dissociation from CMG2 [12]. However, it was proposed that LF rarely translocates directly to the cytosol from the limiting membrane of endosomes; more frequently it is delivered to intralumenal vesicles (ILVs) which then release the toxin upon back-fusion with the limiting membrane at the LE stage [13-15]. EF was found to remain attached to the cytosolic side of LE membrane, whereas LF freely diffuses into the cytosol $[13,16,17]$.

$\mathrm{EF}$ and LF act on many cell types, but their action on cells of both innate and adaptive immunity appears particularly relevant 
as it allows $B$. anthracis to survive the host defense mechanisms. In some cell types, the two toxins act in synergism $[18,19]$. EF and LF affect fundamental signaling pathways linking extracellular stimuli to cell function. LF is a $\mathrm{Zn}$-dependent metalloprotease that cleaves the $\mathrm{N}$-terminal portion of most isoforms of the mitogen activated protein kinase kinases (MAPKKs or MEKs) [20], thus disrupting MEK-dependent signaling [5,19]. The action of EF is less understood. EF is a calmodulin-dependent adenylate cyclase that perturbs ion homeostasis and cell signaling by increasing the cytosolic cAMP concentration [5,19]. Injection of PA+EF (edema toxin, EdTx) into mice causes tissue lesion and death [21].

EdTx-induced alterations of cell signaling are generally thought to be inhibitory and to be mediated by cAMP-dependent protein kinase (PKA) [19]. In particular, $\mathrm{CD}^{+} \mathrm{T}$ cells were identified as targets of anthrax toxins in vitro and ex vivo [22-24]. EdTx is able to suppress $\mathrm{T}$ cell proliferation and to inhibit cytokine release $[22,24]$. MEK, ERK and JNK phosphorylation were found to be affected by EdTx in cells activated by $\mathrm{T}$ cell receptor (TCR) crosslinking, which resulted in reduced activity of the transcription factors NF-AT and AP-1 [22,24]. Similarly, EdTx inhibits T cell chemotaxis by downregulation of ERK phosphorylation [25]. These effects were attributed to the inhibitory action of PKA on upstream kinases of the MAPK family, among which Raf. Nevertheless, targets of PKA in EdTx-triggered signaling are scarcely defined.

Using Jurkat T cells, we studied the impact of EdTx-mediated intracellular cAMP elevation on PKA- and cAMP response element binding protein (CREB)-dependent signaling and demonstrated that EdTx activates gene expression. We report that EdTx generates an extremely enduring increase in cAMP levels, which stimulates nuclear translocation of the PKA catalytic subunit and phosphorylation of CREB. This in turn allows binding of phosphorylated CREB (pCREB) to chromatin and transcription of a reporter gene under control of the cAMP response element (CRE). Further, we found that pre-treatment with EdTx prevents phosphorylation of CREB induced by a cAMP stimulus or by TCR cross-linking. Comparison with other cAMP-elevating agents showed that length and site of cAMP synthesis are crucial to modulation of gene transcription, which indicates that prolonged perinuclear production of cAMP is a specific and functional feature of EdTx intoxication mechanism.

\section{Materials and Methods}

\section{Reagents, plasmids, and proteins}

All chemicals were p.a. grade or higher and purchased from Sigma, together with forskolin, cholera toxin (CT), and poly-Dlysine. Protease inhibitor tablets (complete, devoid of EDTA) were purchased from Roche. Adefovir dipivoxil was a kind gift of Gilead (CA, USA). Roswell Park Memorial Institute Medium (RPMI) 1640 and fetal bovine serum (FBS) were bought from Invitrogen. Antibiotics and L-glutamine were purchased from GIBCO. Antibodies against CREB and pCREB (phospho-S133) were purchased from Upstate, against tetra-acetyl-histone H4, pRSK1/ 2 p90 (phospho-S380), pMSK1 (phospho-T581) from Abcam, against CD3 (OKT3) from eBioscience, against actin from Sigma. Secondary antibodies and $\mathrm{H}-89$ dihydrochloride were obtained from Calbiochem. Plasmids pcDNA3-RII-GFP and pcDNA3-CYFP coding, respectively, for the regulatory subunit of PKA fused to cyan fluorescent protein and for the catalytic subunit of PKA fused to yellow fluorescent protein were as in [26]. Plasmids pCRE-Luc and pRL-TK were obtained from Clontech and Promega, respectively. PA [27], EF [16], and CyaA [28] were prepared as previously described. Endotoxin contamination was monitored with PyroGene-rFG Endotoxin Detection System (Lonza) and was found in all preparations to be below 0.5 endotoxin units/ $\mu \mathrm{g}$ protein.

\section{Cell culture}

E6.1 Jurkat T cells were kept in RPMI 1640, supplemented with $100 \mathrm{U} / \mathrm{ml}$ penicillin, $100 \mu \mathrm{g} / \mathrm{ml}$ streptomycin, $2 \mathrm{mM}$ L-glutamine, $10 \mathrm{mM}$ Hepes and 10\% heat-inactivated FBS. Cells were maintained at $37^{\circ} \mathrm{C}$ and $5 \% \mathrm{CO}_{2}$ in a humid environment.

\section{Cell viability test}

Viability of Jurkat cells was assessed by measuring the oxidation of 3-(4,5-dimethylthiazol-2-yl)-5-(3-carboxymethoxyphenyl)-2-(4sulfophenyl)-2H-tetrazolium) (MTS) using the CellTiter96 Aqueous One Solution Cell Proliferation Assay (Promega) 12 h, 24 h, $48 \mathrm{~h}$, and $72 \mathrm{~h}$ after treatment with $10 \mathrm{nM} \mathrm{EF}+40 \mathrm{nM}$ PA (final concentration hereafter), $3 \mathrm{nM} \mathrm{CT,} 5 \mathrm{nM}$ CyaA, $25 \mu \mathrm{M}$ forskolin (in DMSO, from a $10 \mathrm{mM}$ stock solution), 1:400 (vol/vol) DMSO, $10 \mathrm{nM} \mathrm{EF}$, or $40 \mathrm{nM}$ PA.

\section{Determination of the cellular content of CAMP}

$5 \times 10^{5}$ Jurkat cells in $200 \mu \mathrm{l}$ were prepared the evening before the determination and stimulated for the indicated times with $10 \mathrm{nM} \mathrm{EF}+40 \mathrm{nM}$ PA, $3 \mathrm{nM}$ CT, $5 \mathrm{nM}$ CyaA, $25 \mu \mathrm{M}$ forskolin, or left untreated. $5 \mu \mathrm{M}$ adefovir dipivoxil (in DMSO, from a $0.5 \mathrm{mM}$ stock solution) was added 2 to $12 \mathrm{~h}$ before stimulation with EdTx and was reapplied $4 \mathrm{~h}$ after the first addition. Samples were prepared in triplicates. The culture medium was removed after $10 \mathrm{~min}$ of centrifugation at $1300 \mathrm{rpm}$ and $4^{\circ} \mathrm{C}$ and the cells immediately processed for intracellular cAMP measurement by enzyme-linked immunoassay following the manufacturer's instruction (Biotrak EIA, GE Healthcare). The number of cells present in each sample was determined separately using a Bürker chamber.

\section{Plasmid preparation and transfection of Jurkat cells}

Plasmids pcDNA3-C-YFP, pcDNA3-RII-CFP, pCRE-Luc, and pRL-TK were propagated in $\mathrm{CaCl}_{2}$-competent Escherichia coli XL1Blue cells that were transformed by the heat shock method [29]. To purify plasmid DNA, a Maxi-Prep (QIAGEN) was performed according to the manufacturer's instructions. $9 \times 10^{6}$ of Jurkat cells in $30 \mathrm{ml}$ of culture medium were prepared the evening before transfection. $20 \mu \mathrm{g}$ each of pcDNA3-RII-CFP and pcDNA3-CYFP or $20 \mu \mathrm{g}$ pCRE-Luc and $1 \mu \mathrm{g}$ pRL-TK were introduced into cells kept in $400 \mu \mathrm{l}$ of culture medium devoid of FBS giving an electric shock at $250 \mathrm{~V}$ and $950 \mathrm{~F}$ in electroporation cuvettes with $0.4 \mathrm{~cm}$ gap (Bio-Rad) using a GenePulser Xcell electroporator (Bio-Rad). The FBS content was brought back to $10 \%$ and cells allowed to grow a few hours at a concentration of $5 \times 10^{5}$ cells $/ \mathrm{ml}$.

\section{Imaging of the nuclear translocation of PKA catalytic subunit}

$48 \mathrm{~h}$ after transfection with pcDNA3-RII-CFP and pcDNA3-CYFP, cells were stimulated with $10 \mathrm{nM} \mathrm{EF}+40 \mathrm{nM} \mathrm{PA}, 3 \mathrm{nM} \mathrm{CT}$, $5 \mathrm{nM}$ CyaA, $25 \mu \mathrm{M}$ forskolin, or left untreated and at the indicated times allowed to adhere for $10 \mathrm{~min}$ to cover slips coated with poly-D-lysine $(50 \mu \mathrm{g} / \mathrm{ml})$. Cells were paraformaldehyde-fixed according to standard protocols. Z-stacks of samples with $0.27 \mu \mathrm{m}$ width were acquired at $490 \mathrm{~nm}$ on a DMIRE2 fluorescence microscope (Leica), equipped with a Leica DC 500 CCD camera, using a $63 \times$ oil immersion objective with NA 1.4 and $1.5 \times$ magnification. Images were deconvoluted with the software LeicaDeblur and the maximal projection created in WCIF Image $\mathrm{J}[30]$. 


\section{Western blotting}

Jurkat cells were treated for the indicated times with $10 \mathrm{nM}$ $\mathrm{EF}+40 \mathrm{nM}$ PA, $3 \mathrm{nM}$ CT, $5 \mathrm{nM}$ CyaA, $25 \mu \mathrm{M}$ forskolin, or left untreated. To induce TCR cross-linking, cells were transferred for $30 \mathrm{~min}$ to plates coated over night with antibody against CD3 $\left(10 \mu \mathrm{g} / \mathrm{ml}\right.$ in PBS). Samples containing $10^{5}$ cells were lysed on ice for $10 \mathrm{~min}$ under rotation in the presence of protease inhibitors and heated for $8 \mathrm{~min}$ to $95^{\circ} \mathrm{C}$ in $60 \mu \mathrm{l} \mathrm{Laemmli}$ buffer [31]. $10 \mu \mathrm{g}$ of protein per lane were subjected to SDS-PAGE on $12 \%$ polyacrylamide gels at room temperature and $20 \mathrm{~mA}$ per gel and transferred at $200 \mathrm{~mA}$ to nitrocellulose in a refrigerated chamber. Membranes were incubated with the appropriate antibodies following the manufacturer's instructions. When necessary, membranes were stripped by $30 \mathrm{~min}$ incubation at $50^{\circ} \mathrm{C}$ in $62.5 \mathrm{mM}$ Tris/HCl pH 6.7, 2\% (w/v) SDS, $1 \mathrm{mM}$ 2-mercaptoethanol, thoroughly rinsed and re-probed. Chemiluminescence was developed with ECL Plus or ECL Advance western blotting detection system (GE Healthcare) and emission was measured with ChemiDoc XRS (Bio-Rad). Band intensities were quantified on the original files with the software Quantity One (Bio-Rad). None of the bands was saturated. Band intensities of blots against CREB, pCREB, pRSKl/2 and pMSK1 were corrected with the intensities of the loading control actin and set equal to 1 at $t=0$.

\section{Luminescence assay}

The day after transfection with pCRE-Luc and pRL-TK, cells were stimulated with $10 \mathrm{nM} \mathrm{EF}+40 \mathrm{nM}$ PA, $3 \mathrm{nM}$ CT, $5 \mathrm{nM}$ CyaA, or $25 \mu \mathrm{M}$ forskolin. As controls, 1:400 (vol/vol) DMSO, $10 \mathrm{nM} \mathrm{EF}$, or $40 \mathrm{nM}$ PA were added or cells were left untreated. Cells were lysed on ice for $10 \mathrm{~min}$ in the presence of protease inhibitors and luciferase activity was assayed immediately using the Dual-Luciferase Reporter Assay System (Promega) as described by the manufacturer. For each time point, $10^{5}$ cells were present. Samples were prepared in triplicates. For every

\section{EdTx}

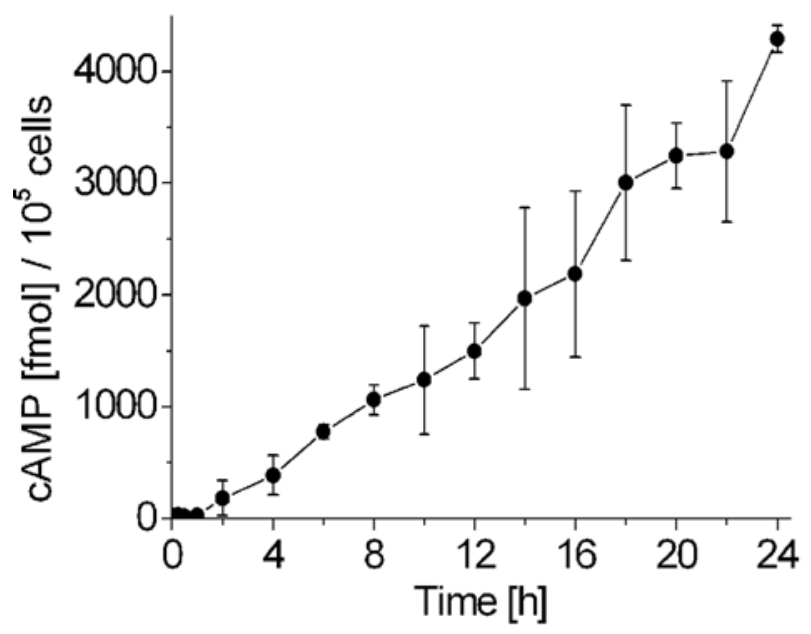

\section{CyaA}
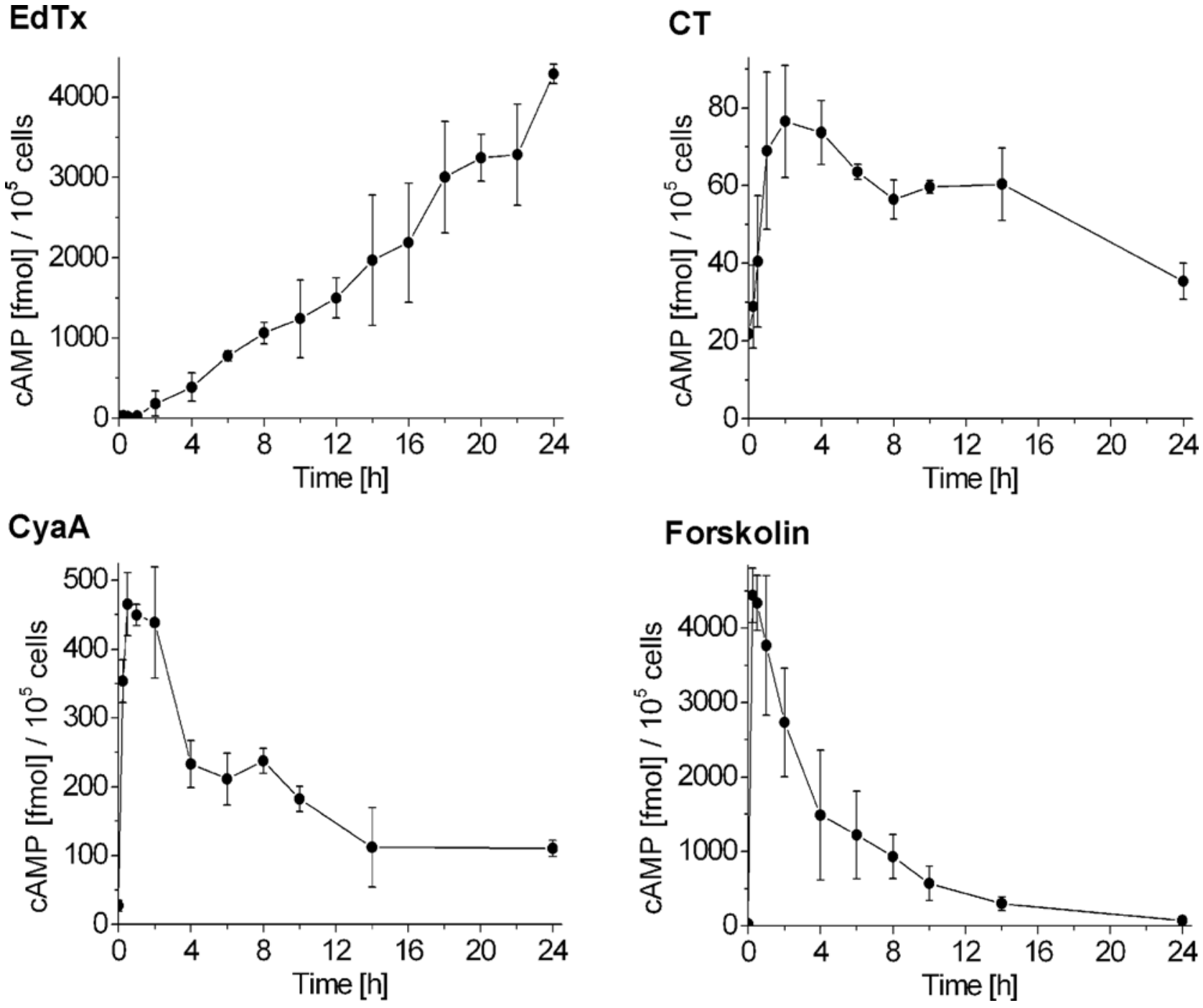

Forskolin

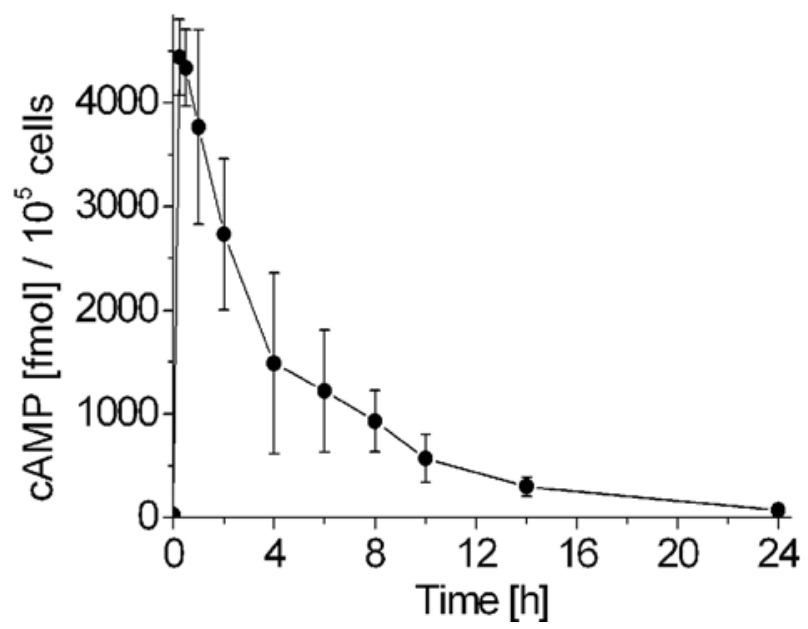

Figure 1. Time course of cAMP production by Jurkat cells stimulated with EdTx, CT, CyaA, or forskolin. Jurkat T cells were stimulated for the indicated times with EdTx (10 nM EF+40 nM PA), CT (3 nM), CyaA (5 nM), or forskolin $(25 \mu \mathrm{M})$. At the end of the incubations, the samples, which contained $10^{5}$ cells, were lysed and immediately subjected to competition ELISA in order to determine the amount of cAMP present. Adefovir dipivoxil, a specific inhibitor of EdTx, abolished cAMP synthesis in EdTx-treated cells (not shown). Note the different cAMP scales in the four panels. Experiments were not normalized to percentage values to provide the actual levels of cAMP. Data are the mean and standard deviation of four independent experiments for EdTx and three for CT, CyaA and forskolin, performed in triplicates.

doi:10.1371/journal.pone.0003564.g001 
sample, both the ratio between the luminescence of firefly and renilla luciferases and the firefly luciferase activity per $\mu \mathrm{g}$ of protein in cell lysates were obtained. Proteins were quantified by the Bradford method (Biorad Protein Assay).

\section{Chromatin immunoprecipitation}

The evening before the experiment, $5 \times 10^{5}$ Jurkat cells were inoculated into $2 \mathrm{ml}$ culture medium. The following day, they were treated for the indicated times with $10 \mathrm{nM} \mathrm{EF}+40 \mathrm{nM}$ PA, or $3 \mathrm{nM} \mathrm{CT}$, or $5 \mathrm{nM} \mathrm{CyaA}$, or $25 \mu \mathrm{M}$ forskolin, or DMSO $(1: 400 \mathrm{vol} / \mathrm{vol})$, or left untreated. Proteins and DNA were crosslinked by addition of $1 \%(\mathrm{w} / \mathrm{v})$ formaldehyde directly to the culture medium and incubation for $10 \mathrm{~min}$ at $37^{\circ} \mathrm{C}$. The reaction was stopped with $125 \mathrm{mM}$ glycine in PBS. Cells were washed with ice-cold PBS containing protease inhibitors and lysed on ice for $10 \mathrm{~min}$ under rotation in the presence of protease inhibitors. DNA was sheared to fragments of about $600 \mathrm{bp}$ by three cycles of $10 \mathrm{~s}$ of ultrasonic dispersion using a Fisher Sonic Dismembrator Model 300 at $30 \%$ power output with a $4 \mathrm{~mm}$ tip. The lysates were subjected to chromatin immunoprecipitation according to the manufacturer instructions using the kit produced by Upstate, including standard controls such as absence of antibody and presence of unspecific rabbit IgG. $15 \mu \mathrm{l}$ of anti-pCREB antibody were employed. Samples were processed for SDS-PAGE and subjected to western blotting with an antibody against tetra-acetylhistone $\mathrm{H} 4$.

\section{Results}

\section{Time course of cAMP production}

The concentrations of the toxins and drugs used here were deduced from the literature. In fact, the concentration of EdTx, CT, and CyaA in circulating fluids during pathogenesis is not yet known.
The selected toxin concentrations were either within or below the affinity range of these toxins for their respective cell surface receptor [32-36]. One can reasonably hypothesize that such toxin concentrations will be found in vivo. In particular, the present concentration of $10 \mathrm{nM}$ EdTx was chosen on the basis of our previous cellular studies $[16,24,25]$ and is by far lower than the estimated $150 \mathrm{nM}$ tissue fluid concentration used in a recent study of EdTx toxicity in mice [21]. Indeed, cell viability and growth were unaffected by EdTx, CT, CyaA, and forskolin at the concentrations we employed for the duration of the experiments (not shown).

The time course of total intracellular cAMP synthesis in Jurkat $\mathrm{T}$ cells following treatment with EdTx, CT, CyaA and forskolin was determined by competition ELISA. Although this approach is not as sensitive as the previously used FRET-based live imaging of intracellular cAMP production [16], it allows to measure the total cAMP content over a prolonged period of time. All four agents induced a rise of intracellular cAMP levels, however the kinetics and the amounts of produced cAMP strongly differed among them (Fig. 1). Addition of EdTx (10 $\mathrm{nM} \mathrm{EF+40} \mathrm{nM} \mathrm{PA)} \mathrm{lead} \mathrm{to} \mathrm{a} \mathrm{rise} \mathrm{of}$ the intracellular cAMP concentration that was appreciable after $2 \mathrm{~h}$ and, strikingly, increased steadily during the following $24 \mathrm{~h}$, producing up to $4300 \mathrm{fmol}$ of cAMP per $10^{5}$ Jurkat cells. Using FRET-based live imaging of EdTx activity, we previously found that cAMP levels start rising 30-40 min after toxin addition [16]. Synthesis of cAMP was suppressed by adefovir dipivoxil (not shown), a specific inhibitor of EdTx [37]. Stimulation of Jurkat cells with $3 \mathrm{nM}$ CT induced a rapid, but limited rise in intracellular cAMP concentration that attained the highest level $2 \mathrm{~h}$ after toxin addition (about $80 \mathrm{fmol}$ of cAMP per $10^{5}$ cells) and then slowly decayed. Addition of $5 \mathrm{nM}$ CyaA induced an immediate rise in cAMP concentration that reached its maximum 30-60 min after addition with about $450 \mathrm{fmol}$ per $10^{5}$ Jurkat cells, maintained these cAMP levels for another $1.5 \mathrm{~h}$, and then progressively decayed. Forskolin
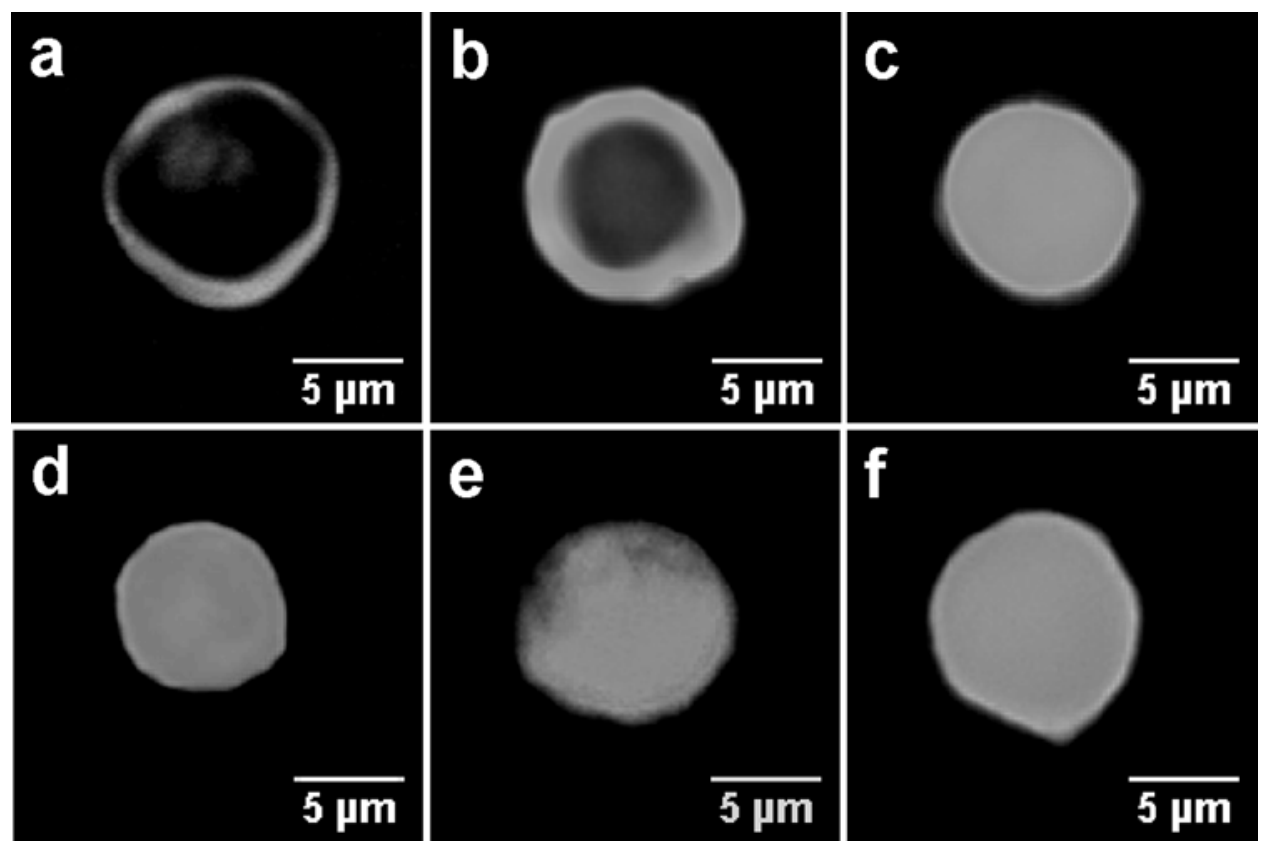

Figure 2. Activation and nuclear translocation of PKA catalytic subunit upon stimulation of Jurkat cells with EdTx, CT, CyaA, or forskolin. Cells were transiently transfected with a fluorescent probe coding for the PKA catalytic subunit fused to yellow fluorescent protein, stimulated with EdTx (10 nM EF+40 nM PA), CT (3 nM), CyaA (5 nM), or forskolin ( $25 \mu \mathrm{M})$, fixed and observed at the microscope. a) in resting cells, the catalytic subunit of PKA resides within the ring-shaped cytoplasm. b) $1.5 \mathrm{~h}$ after addition of EdTx, the majority of the PKA catalytic subunit is still present in the cytosol, whilst c) after $8 \mathrm{~h}$ it is inside the nucleus. The migration of PKA catalytic subunit induced by CT, CyaA, and forskolin after $1.5 \mathrm{~h}$ are shown in panels d), e) and f), respectively.

doi:10.1371/journal.pone.0003564.g002 


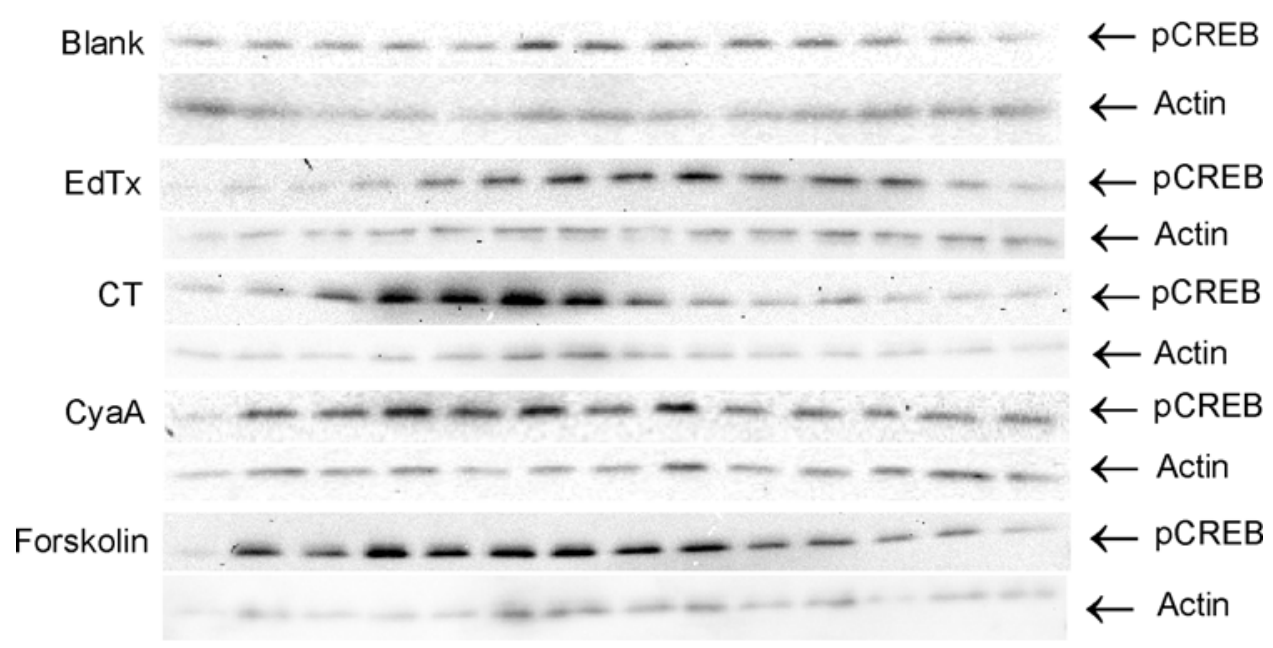

\section{EdTx}

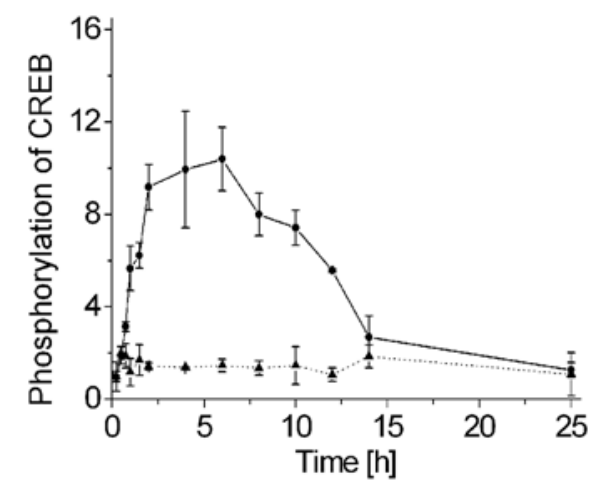

\section{CyaA}

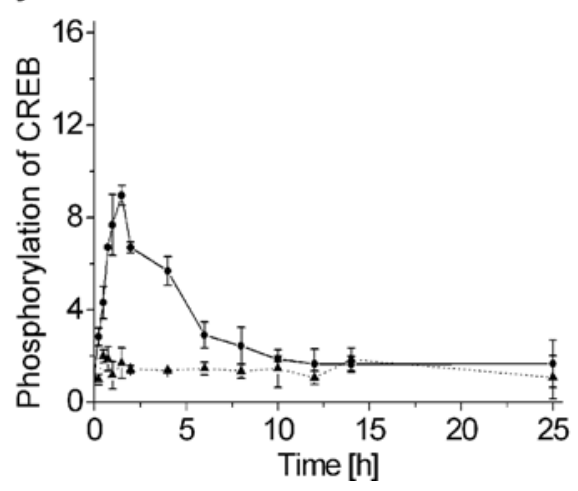

CT

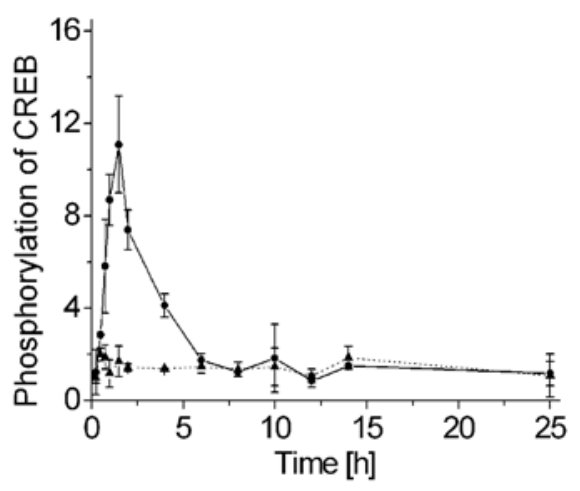

Forskolin

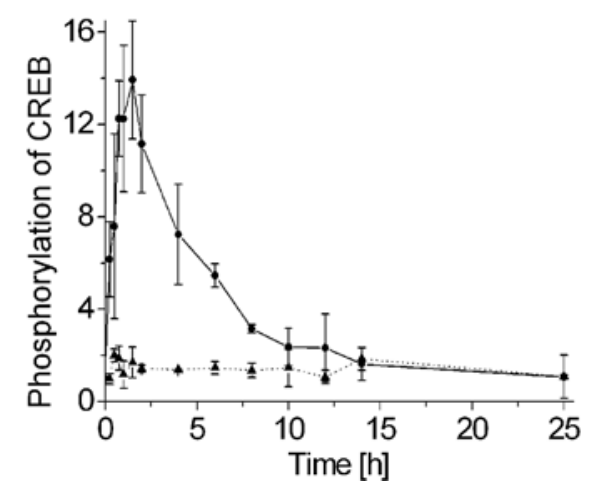

Figure 3. Phosphorylation of CREB upon stimulation of Jurkat cells with EdTx, CT, CyaA, or forskolin. Cells were stimulated for the indicated times, lysed and processed for western blotting using an antibody against S133-pCREB. On each lane $10 \mu \mathrm{g}$ of protein were loaded. Upper panel, western blots depicting the time course of EdTx (10 nM EF+40 nM PA), CT (3 nM), CyaA (5 nM), and forskolin ( $25 \mu \mathrm{M})$ dependent CREB phosphorylation. Lower panels, the graphs report the quantitative analysis of the kinetics of CREB phosphorylation induced by EdTx, CT, CyaA, and forskolin (solid line with filled circles). Untreated samples are depicted by the dotted line with black triangles. The intensity of each band was determined using the software Quantity One (Bio-Rad) and was corrected for different loadings using the corresponding value of actin as control. The value at time 0 was set equal to 1. The total amount of cellular CREB did not change during the time course of CREB phosphorylation (not shown). The blots show one representative experiment and the data in the graphs are the mean and standard deviation of three independent experiments. doi:10.1371/journal.pone.0003564.g003 
$(25 \mu \mathrm{M})$ caused a rapid $(15 \mathrm{~min})$ and sharp peak of cAMP concentration with 4400 fmol of cAMP per $10^{5}$ Jurkat cells.

\section{Activation of PKA}

Next, we tested the possibility that the toxin- or forskolininduced rise in cAMP concentration could activate PKA and drive the consequent nuclear translocation of its catalytic subunit. We imaged PKA in cells by transiently expressing a fluorescent probe consisting of the PKA catalytic subunit fused to YFP. As expected, in resting Jurkat cells the catalytic subunit of PKA resided in the ring-shaped cytosol (Fig. 2a). To the contrary, upon stimulation with EdTx (10 nM EF+40 nM PA), CT (3 nM), CyaA (5 nM), or forskolin $(25 \mu \mathrm{M})$ the catalytic subunit translocated to the nucleus (Fig. 2b-f). According to the respective kinetics of intracellular cAMP increase of the different toxins, the catalytic subunit of PKA diffused into the nucleus with different time courses.

\section{Phosphorylation of CREB}

This result suggested to study the functional consequence of the nuclear migration of PKA on the phosphorylation of CREB, which is the best characterized cAMP-regulated transcription factor [38-41]. Western blot analysis of the active, S133phosphorylated form of CREB from EdTx (10 nM EF+40 nM PA), CT $(3 \mathrm{nM})$, CyaA $(5 \mathrm{nM})$, or forskolin $(25 \mu \mathrm{M})$ stimulated cells are shown in Fig. 3. A precise quantification of CREB phosphorylation kinetics was then obtained from the ratios of the pCREB signal to that of the actin level, which were determined on the same blots with an actin-specific antibody (not shown). The time course of CREB phosphorylation resembled the time course of cAMP production, except for EdTx at late time points. Indeed, EdTx action started with a delay of about $45 \mathrm{~min}$ and then exhibited a strongly sustained CREB phosphorylation, which reached the maximum around $6 \mathrm{~h}$ (Fig. 3). Notably, a high level of pCREB was maintained until $12 \mathrm{~h}$ after toxin addition, but it then returned to basal levels in spite of the rising concentration of intracellular cAMP (Fig. 1), most likely owing to the activation of negative feedback mechanisms [41]. CT had a lag of about $45 \mathrm{~min}$ before significant CREB phosphorylation could be observed, which peaked $1.5 \mathrm{~h}$ after stimulation and came down to basal levels after $6 \mathrm{~h}$ (Fig. 3). At the maxima, the amounts of pCREB produced in response to CT were comparable to those produced by EdTx. CyaA triggered a very rapid phosphorylation of CREB (appreciable $15 \mathrm{~min}$ after toxin addition), reaching a maximum after $1.5 \mathrm{~h}$ and followed by a smooth decay that was completed after 10-12 h (Fig. 3). At their maxima, the quantity of pCREB produced by CyaA was comparable to those induced by EdTx and CT. Finally, forskolin mediated a time course of CREB phosphorylation that was very similar to that of CyaA (Fig. 3). However, at the maximum, the amount of pCREB synthesized in response to forskolin was higher than in the presence of EdTx, CT, and CyaA. The total cellular amount of CREB, which was assayed on the same samples by western blotting with an antiCREB antibody, did not vary during the treatment with EdTx, CT, CyaA, and forskolin (not shown). These cAMP-elevating agents also induced phosphorylation of the CREB-related transcription factor ATF-1, which was observable by western blot with the anti-pCREB antibody owing to the common presence of a phosphorylated serine epitope (not shown).

\section{Specificity of CREB phosphorylation by PKA}

We further addressed the question whether phosphorylation of CREB depended only on PKA or also on other factors that could be activated by cAMP in Jurkat $\mathrm{T}$ cells. To this end, we monitored EdTx-, CT-, CyaA-, and forskolin-mediated CREB phosphorylation in the presence and absence of the inhibitor H-89 dihydrochloride, which is commonly used to discriminate between the effects of PKA from those of other kinases, as well as of the guanine nucleotide exchange factor Epac. Epac can induce phosphorylation of CREB in a Rapl- and MAPK-dependent way $[38,42,43]$ and was found to mediate EdTx-induced inhibition of endothelial cell chemotaxis [44]. In the presence of $20 \mu \mathrm{M} \mathrm{H}-89$, CREB phosphorylation induced by EdTx (10 nM EF+40 nM PA), CT (3 nM), CyaA (5 nM), or forskolin $(25 \mu \mathrm{M})$ was strongly inhibited (Fig. 4). However, H-89 has been reported to affect the activity of mitogen/stress activated kinases [45], which can phosphorylate CREB [39-41] and, interestingly, CREB phosphorylation during T cell activation is dependent on RSK2 [46,47] and MSK1 [48]. We therefore verified whether this kinase family might have been activated in $\mathrm{T}$ cells by the cAMP-modulating toxins. Jurkat cells were incubated with EdTx, CT, CyaA, or forskolin over a range of $24 \mathrm{~h}$ and analyzed by western blotting using antibodies directed against the active, S380-phosphorylated isoforms 1 and 2 of p90 ribosomal S6 kinase (RSK) and against the active, T581-phosphorylated mitogen- and stress-activated protein kinase (MSK) 1 . We found that the phosphorylation levels of RSK1/2 and of MSK1 were not affected by any of the toxin or drug added (not shown).

\section{Expression of a CRE-driven reporter gene}

To test whether the phosphorylation of CREB described above could lead to gene transcription through its cognate activator sequence cAMP response element (CRE), Jurkat cells were doubletransfected with two plasmids, one coding for firefly luciferase under the control of CRE and the other coding for renilla luciferase under the control of a viral promoter with constitutive transcriptional activity. Stimulation of pCREB transcriptional activity in the transfected cells will result in an increase of the ratio of firefly luciferase activity to that of renilla luciferase activity. Indeed, as shown in Fig. 5, EdTx (10 nM EF+40 nM PA), CT

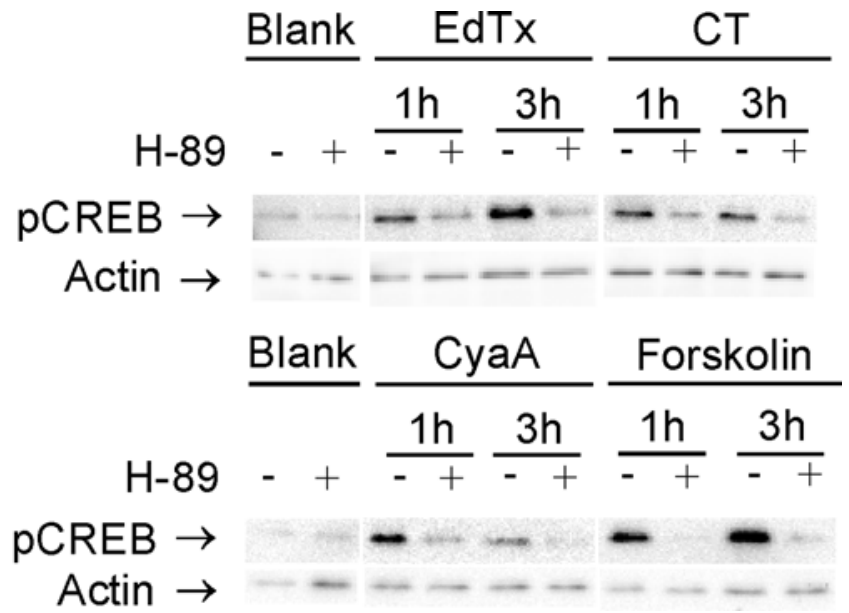

Figure 4. PKA-dependent phosphorylation of CREB upon stimulation of Jurkat cells with EdTx, CT, CyaA, or forskolin. Cells were stimulated for the indicated times with EdTx (10 nM $\mathrm{EF}+40 \mathrm{nM} \mathrm{PA}), \mathrm{CT}(3 \mathrm{nM}), \mathrm{CyaA}(5 \mathrm{nM})$, or forskolin $(25 \mu \mathrm{M})$ in the presence or absence of $20 \mu \mathrm{M} \mathrm{H}-89$ dihydrochloride, an inhibitor of PKA, lysed and processed for western blotting using an antibody against S133-pCREB. On each lane $10 \mu \mathrm{g}$ of protein were loaded. Different loading was controlled by staining against actin. In separate experiments, RSK1/2 and MSK1, which mediate CREB phosphorylation during $T$ cell activation, were found not to be activated following $T$ cell stimulation with EdTx, CT, CyaA and forskolin (not shown). The experiment shown is representative of four performed. doi:10.1371/journal.pone.0003564.g004 
(3 nM), CyaA ( $5 \mathrm{nM})$, or forskolin $(25 \mu \mathrm{M})$ were able to stimulate expression of the CRE-controlled gene. In the presence of EdTx no activation of firefly luciferase expression could be detected before $3 \mathrm{~h}$ after addition, compared to $1.5 \mathrm{~h}$ in the presence of CT, CyaA and forskolin. In the same samples, firefly luciferase activity per $\mu \mathrm{g}$ of protein in cell lysates was also determined and very similar results were obtained (not shown).

\section{Duration of pCREB binding to chromatin and transcriptional activation}

The use of a reporter system has shown that EdTx, CT, CyaA, and forskolin are capable of inducing expression of a gene regulated by CRE. However, a CRE-driven reporter assay is a

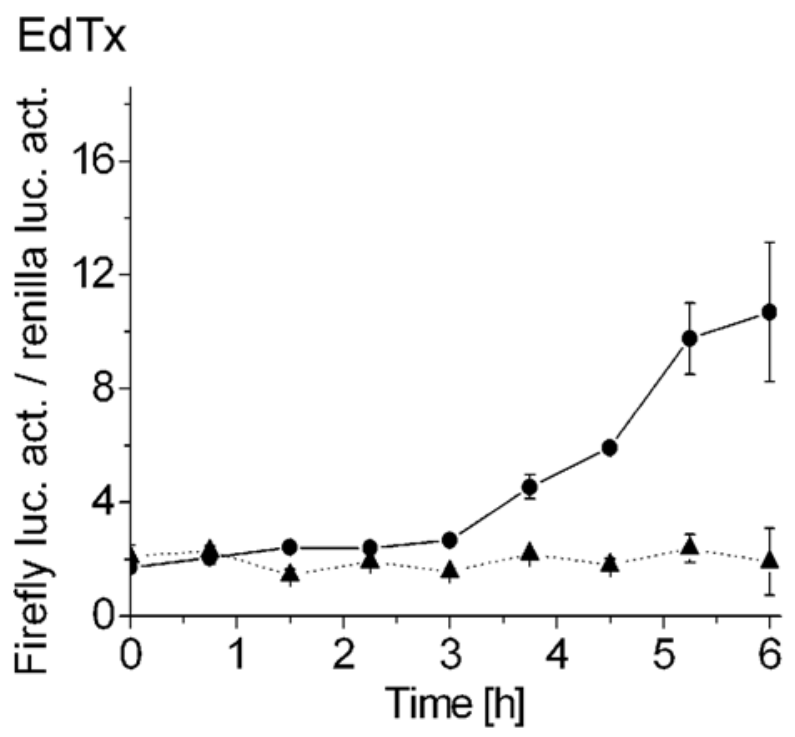

CyaA

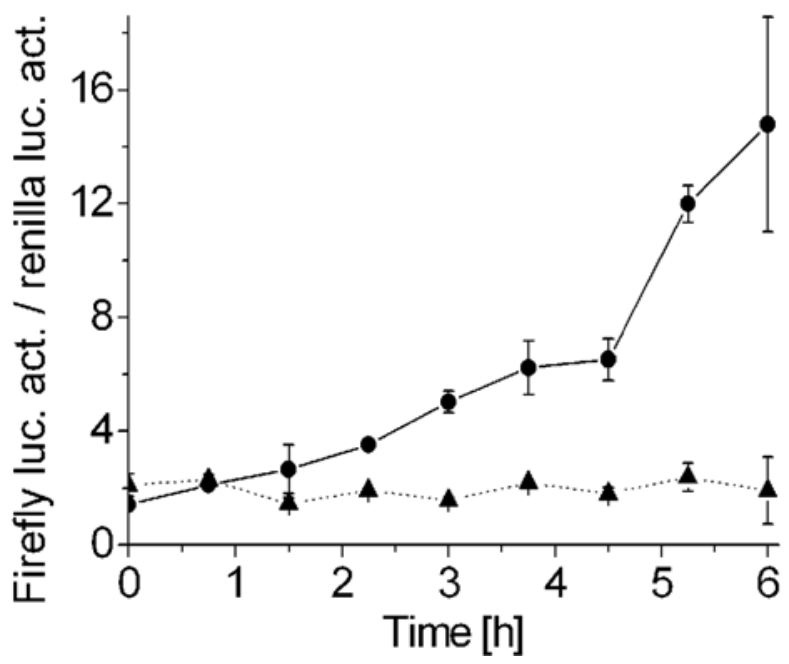

highly simplified system with respect to transcription of cellular genes, where several distinct promoter sequences control this process. Therefore, to test for the association of pCREB with transcriptionally active genomic DNA, we immunoprecipitated pCREB and determined the amount of associated chromatin by western blotting with an antibody specific for the acetylated histone $\mathrm{H} 4$, which is present in CREB-activated genes [49,50]. Fig. 6 shows that EdTx, CT, CyaA, and forskolin are able to promote the association of pCREB with transcriptionally active chromatin, as the amount of precipitated pCREB-bound DNA increased following their addition with respect to untreated samples. However, the duration of pCREB binding to chromatin induced by the different cAMP-elevating agents varied significantly. In fact, whereas EdTx and CT triggered an enduring

\section{CT}

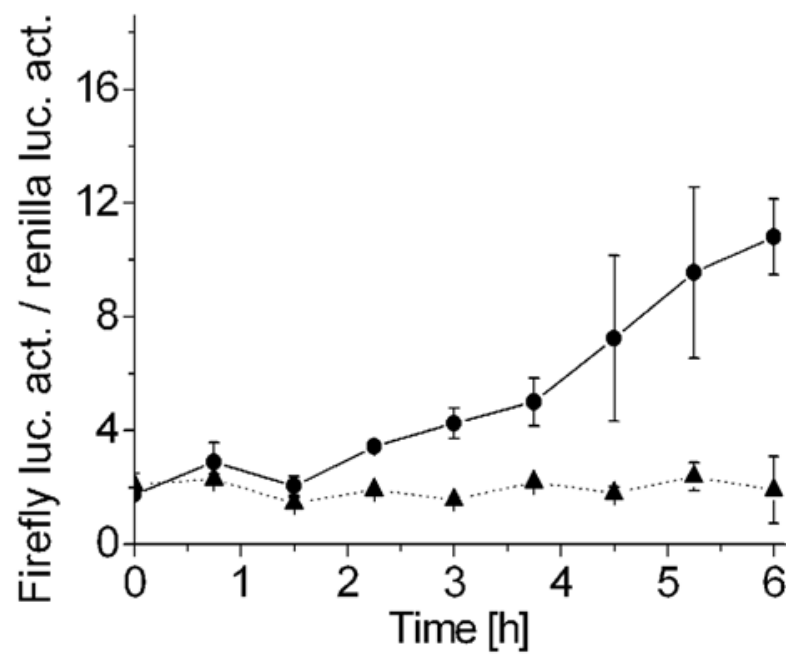

\section{Forskolin}

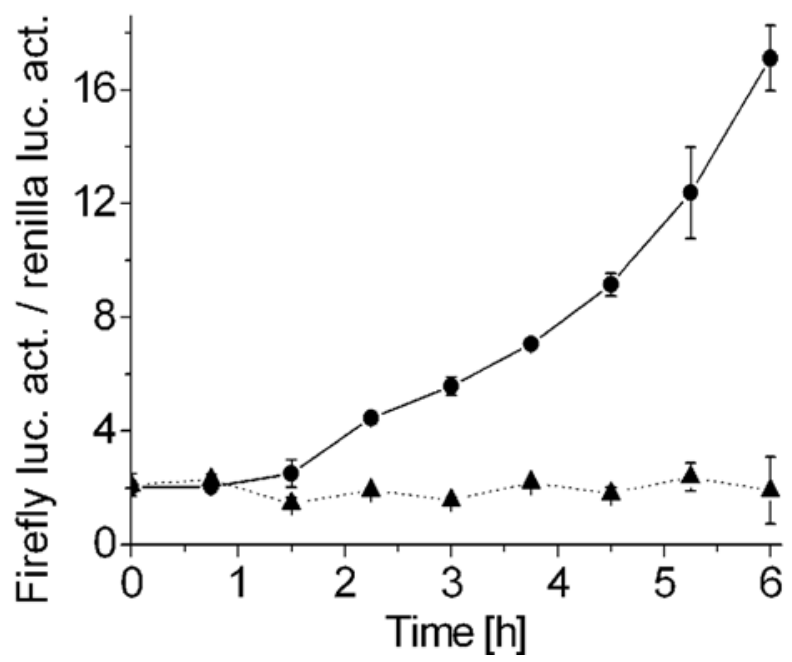

Figure 5. Expression of a reporter gene under the control of CRE upon stimulation of Jurkat cells with EdTx, CT, CyaA, or forskolin. Cells were double-transfected with plasmids coding for firefly luciferase under the control of the inducible promoter CRE and for renilla luciferase under the control of a viral promoter with basal transcriptional activity. Each sample contained $10^{5}$ cells that were lysed and immediately processed for a chemiluminescence assay. The ratio between the activity of firefly and renilla luciferases is plotted. An increasing value of this ratio indicates that the gene regulated by CRE is expressed. Samples stimulated with EdTx (10 nM EF+40 nM PA), CT ( $3 \mathrm{nM})$, CyaA (5 nM), or forskolin (25 $\mu \mathrm{M})$ are depicted by solid lines with filled circles, whereas untreated samples are represented by dotted lines with filled triangles. EF and PA alone failed to mediate expression of firefly luciferase, whilst DMSO induced a very slight response (not shown). For every sample, firefly luciferase activity per $\mu \mathrm{g}$ of protein in cell lysates was also obtained, giving very similar results (not shown). The data are the mean and standard deviations of four independent experiments performed in triplicates.

doi:10.1371/journal.pone.0003564.g005 


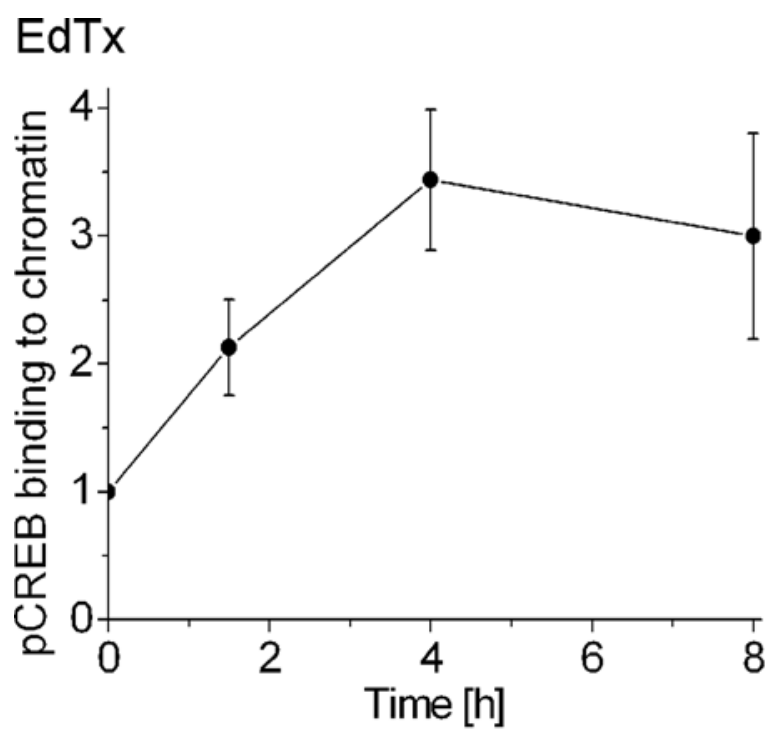

CyaA

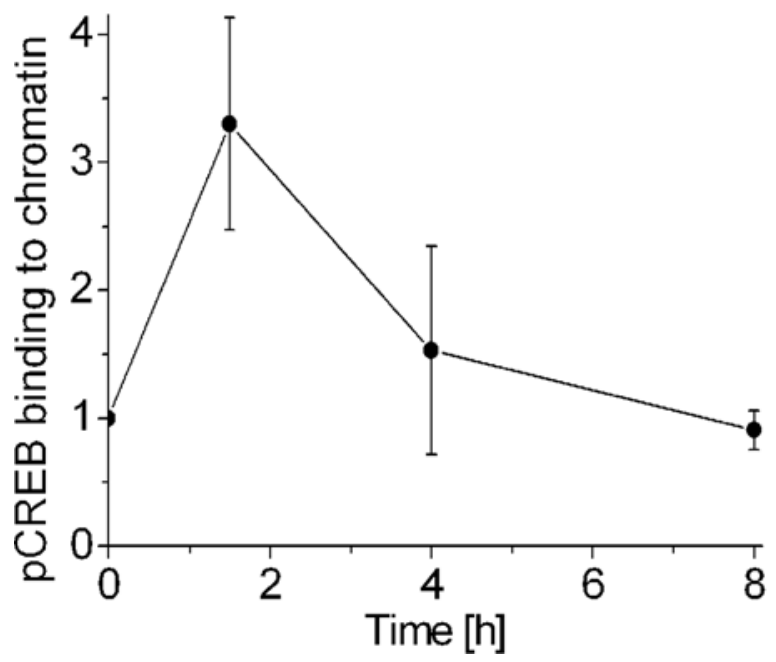

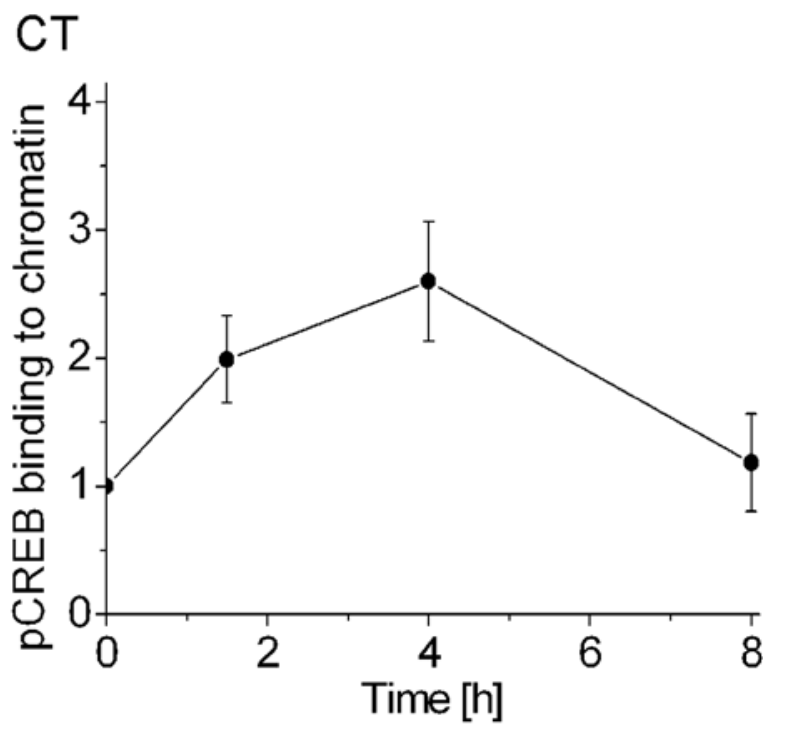

Forskolin

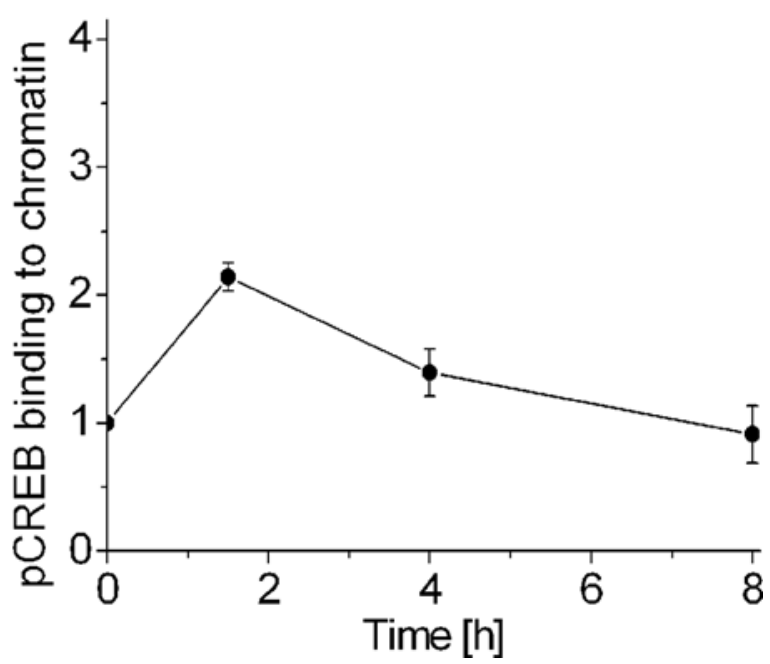

Figure 6. Duration of pCREB binding to chromatin upon stimulation of Jurkat cells with EdTx, CT, CyaA, or forskolin. Cells were treated for the indicated times with EdTx (10 nM EF+40 nM PA), CT (3 nM), CyaA (5 nM) and forskolin ( $25 \mu \mathrm{M})$. Protein and DNA were cross-linked with formaldehyde, then cells were lysed and chromatin was sheared to $600 \mathrm{bp}$ fragments by sonication. Fragmented, transcriptionally active chromatin binding PCREB was recovered by immunoprecipitation of chromatin with a S133-pCREB specific antibody and quantified by western blotting using an antibody specific for acetylated histone $\mathrm{H} 4$, which is present in transcriptionally active DNA. The amount of precipitated chromatin at $\mathrm{t}=0$ was set equal to 1 . DMSO, the vehicle of forskolin, induced a very slight increase in $\mathrm{pCREB}$ association with transcriptionally active chromatin (not shown). The data shown are the mean and standard deviations of three independent experiments. doi:10.1371/journal.pone.0003564.g006

binding of pCREB to chromatin, the effects of CyaA and forskolin declined much more rapidly.

\section{Inhibition of CREB phosphorylation in cells pre-treated with CAMP-rising agents}

The fact that phosphorylation of CREB caused by EdTx was terminated after $14 \mathrm{~h}$ (Fig. 3) in spite of the continuously raising intracellular cAMP concentration (Fig. 1) suggested that negative feedback mechanisms are activated. To test whether these mechanisms could suppress CREB re-phosphorylation after a first activation provoked by EdTx (10 nM EF+40 nM PA), CT (3 nM), CyaA $(5 \mathrm{nM})$, or forskolin $(25 \mu \mathrm{M})$, we treated Jurkat cells with these cAMP-elevating agents for $16 \mathrm{~h}$ or $24 \mathrm{~h}$ (at these time points the levels of pCREB had returned to basal) and then re-stimulated CREB phosphorylation by addition of $25 \mu \mathrm{M}$ forskolin or by anti-
CD3 mediated cross-linking of the TCR. As shown in Fig. 7, EdTx abolished re-phosphorylation of CREB induced both by forskolin and by TCR-cross-linking. At variance, CT strongly inhibited TCR-mediated CREB re-phosphorylation, but not CREB reactivation provoked by forskolin. CyaA slightly diminished CREB re-phosphorylation mediated by forskolin and TCR cross-linking. Restimulation of forskolin-treated cells with the same agent, i. e. forskolin, resulted in strong inhibition of CREB re-activation, but allowed GREB re-phosphorylation following TCR cross-linking.

\section{Discussion}

EdTx-mediated suppression of $\mathrm{T}$ cell activity is generally thought to be achieved by inhibition of MAPK-dependent signaling. The present data indicate that EdTx also targets 


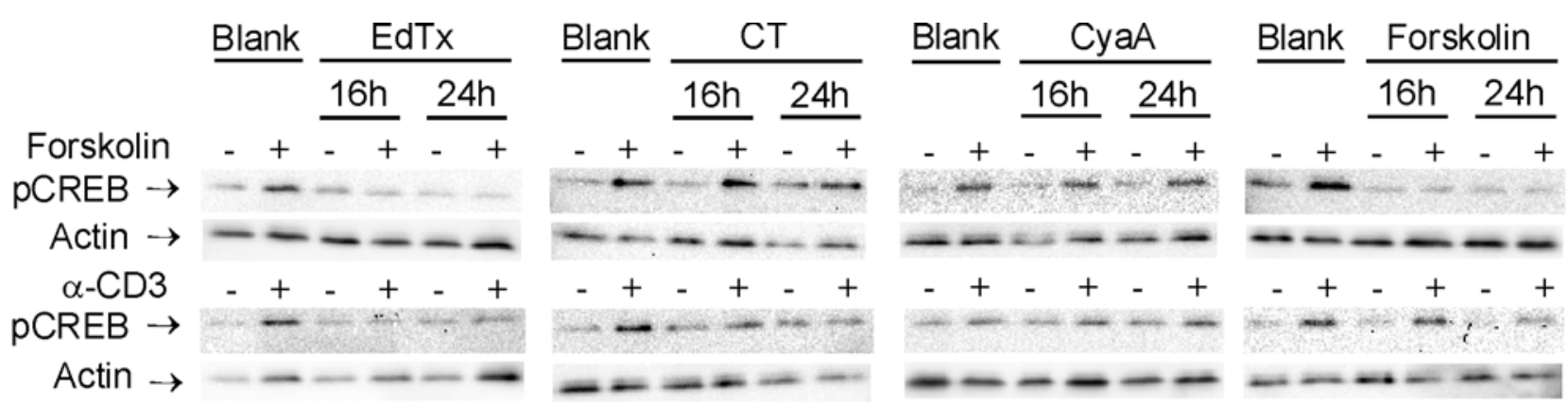

\section{Restimulation: forskolin}

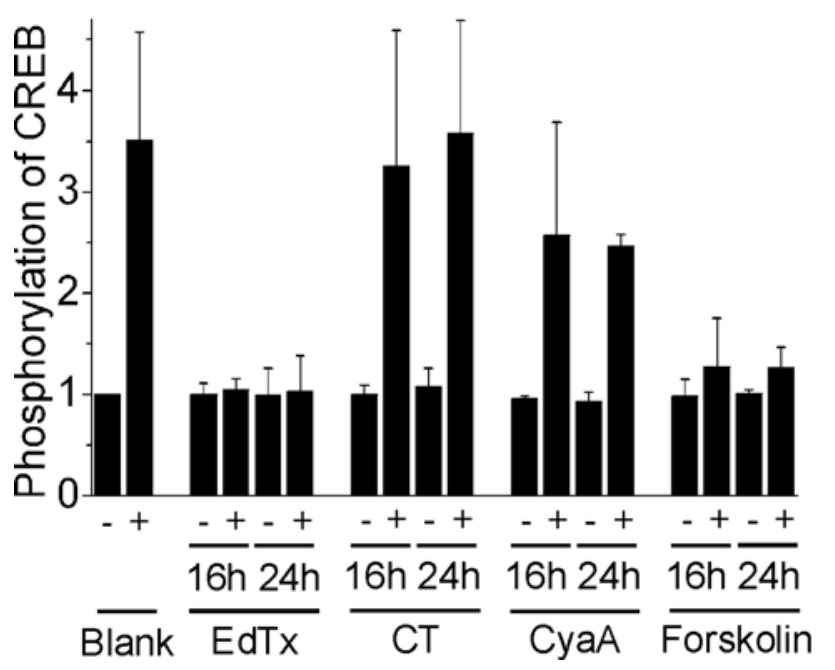

Restimulation: $\alpha-C D 3$

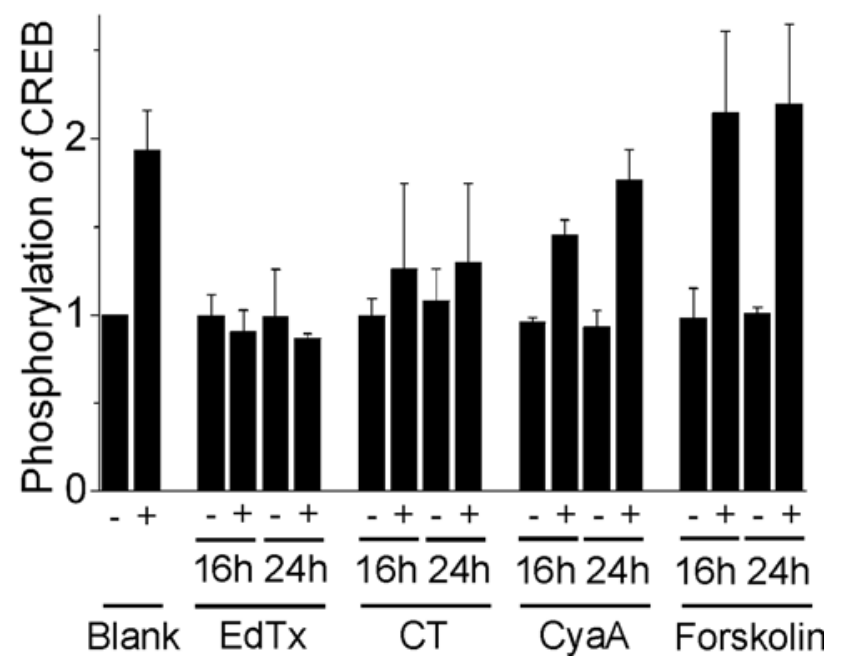

Figure 7. Inhibition of CREB re-phosphorylation in cells pre-treated with EdTx, CT, CyaA or forskolin. Jurkat cells were incubated with EdTx (10 nM EF+40 nM PA), CT (3 nM), CyaA (5 nM), or forskolin ( $25 \mu \mathrm{M})$ and 16 or $24 \mathrm{~h}$ after this first treatment, CREB phosphorylation was restimulated by addition of forskolin $(25 \mu \mathrm{M})$ or by $\alpha$-CD3 antibody mediated cross-linking of the TCR for 30 min. Cells were then lysed and processed for western blotting with antibody against S133-pCREB. The intensity of each band was determined using the software Quantity One (Bio-Rad) and was corrected for different loadings using the corresponding value of actin as control. The value of untreated samples was set equal to 1 . The blots show one representative experiment and the graphs give the mean and standard deviation of three independent experiments. doi:10.1371/journal.pone.0003564.g007

CREB-dependent $\mathrm{T}$ cell signaling. In fact, cAMP synthesis and phosphorylation of CREB are tightly regulated in space and time during $\mathrm{T}$ cell activation $[46,51,52]$ and many of the activated genes are regulated by CRE [46]. Therefore, toxin-mediated alterations of the spatio-temporal synthesis of cAMP appears to be a potent way exploited by pathogens to block $\mathrm{T}$ cell activity.

We report here that EdTx mediates an extremely prolonged rise of cAMP levels, whereas CT-, CyaA- and forskolin-induced elevations of cAMP concentration are transient. This sustained action might be explained either by enduring catalytic activity of EdTx in the cytosol due to high resistance to proteolytic degradation or be linked to its mode of cell entry. In fact, EdTx exploits the endocytic route to reach the cytosol and was proposed to associate with ILVs [13]. These vesicles may function as toxin stores that, upon gradual back-fusion with the limiting membrane of LEs, could progressively release EdTx into the cytosol to produce high amounts of cAMP over a long period of time [15].

The prolonged rise in cAMP levels elicited by EdTx also resulted in long-lasting phosphorylation of CREB. EdTx, CT, CyaA and forskolin were all able to induce transcription of a reporter gene. However, EdTx and, to a lesser extent, CT appeared to be more efficient in promoting enduring pCREB association with transcriptionally active chromatin. This is consistent with the generally accepted finding that stimuli can provoke phosphorylation of CREB with comparable kinetics and stoichiometry, yet not all stimuli are able to induce pCREB-mediated transcription to the same extent $[39,41]$. Clearly, the ability of EdTx, CT, CyaA and forskolin to induce host gene transcription did not correlate with the amount of produced cAMP, as CT mediated only a limited rise of global cAMP levels compared to that triggered by EdTx or forskolin. To the contrary, this effect seems to be strongly influenced by the site of cAMP production. In fact, while CyaA- and forskolin-elicited increase of cAMP concentration is particularly strong below the plasma membrane [16], EdTx [16] and CT [53] cause extensive cAMP rise in the perinuclear region. Indeed, compartmentalization is of prominent importance in cAMP-dependent signaling in many cell types, including $\mathrm{T}$ lymphocytes, as it allows specific interactions of PKA with its targets and therefore distinct signaling outputs [5456]. The present data indicate that perinuclear production of cAMP is particularly efficient in inducing pCREB association with transcriptionally active chromatin. Therefore, localization of the enzymatic activity of EdTx to the perinuclear region appears to be a specific feature of its intoxication mechanism with defined functional consequences. A selected cytosolic localization of the adenylate cyclase activity could explain the reports that Pseudomonas aeruginosa ExoY has distinct effects on endothelial cell permeability 
with respect to the cAMP produced at the level of the plasma membrane [57-59].

CREB mediates expression of a high number of genes that are implicated in a wide array of cell functions, including transcription, cell cycle, and immune regulation $[41,50]$. We found that EdTx-elicited CREB phosphorylation is specifically mediated by PKA, whereas, during $\mathrm{T}$ cell activation, CREB phosphorylation induced by cross-linking of TCR is mainly mediated by proteins of the MAPK pathway, in particular RSK2 [46,47] and MSK1 [48]. RSK1/2 and MSK1 were not phosphorylated upon stimulation with EdTx, in keeping with the finding that EdTx blocks phosphorylation of their upstream kinases MEK and ERK $[22,24]$. This suggests that EdTx and TCR cross-linking may elicit distinct genetic programs. For instance, the genes coding for IL-2, IL-2 receptor, interferon- $\gamma$, tumor necrosis factor $\alpha$, and the early activation marker CD69 contain CRE sites [41,46,60], but their expression was inhibited by EdTx [24]. On the contrary, PKA was reported to downregulate the expression of cyclin D3 and up regulate $\mathrm{p} 27^{\mathrm{kip} 1}$, which block cell growth $[61,62]$. This mechanism could also partially account for EdTx-induced suppression of $\mathrm{T}$ cell proliferation $[22,24]$.

We also report here that, although EdTx initially induces CREB phosphorylation and gene expression, after a prolonged incubation it clearly inhibits the subsequent phosphorylation of CREB induced by forskolin or by TCR cross-linking. This property likely depends on the massive and long-lasting cAMP synthesis caused by EdTx, which probably fuels negative feedback mechanisms of CREB phosphorylation [41]. Interestingly, elevated cAMP levels and hyperactivation of PKA have been implicated in T cell anergy and dysfunction [63]. Possibly, the site of cAMP production might also contribute to inhibition of CREB phosphorylation. Indeed, CT, which similarly induces cAMP elevation in the perinuclear region, was also able to suppress CREB phosphorylation provoked by TCR cross-linking, whereas CyaA and forskolin had a limited effect. These findings indicate that intoxication with EdTx prior to bacterial stimulation of T cells

\section{References}

1. Swartz MN (2001) Recognition and management of anthrax-an update. N Engl J Med 345: 1621-1626.

2. Turnbull PC (2002) Introduction: anthrax history, disease and ecology. Curr Top Microbiol Immunol 271: 1-19.

3. Burnett JC, Henchal EA, Schmaljohn AL, Bavari S (2005) The evolving field of biodefence: therapeutic developments and diagnostics. Nat Rev Drug Discov 4: 281-297.

4. Fouet A, Mock M (2006) Regulatory networks for virulence and persistence of Bacillus anthracis. Curr Opin Microbiol 9: 160-166.

5. Young JA, Collier RJ (2007) Anthrax Toxin: Receptor Binding, Internalization, Pore Formation, and Translocation. Annu Rev Biochem 76: 243-265.

6. Bradley KA, Mogridge J, Mourez M, Collier RJ, Young JA (2001) Identification of the cellular receptor for anthrax toxin. Nature 414: 225-229.

7. Scobie HM, Rainey GJ, Bradley KA, Young JA (2003) Human capillary morphogenesis protein 2 functions as an anthrax toxin receptor. Proc Natl Acad Sci USA 100: 5170-5174.

8. Wei W, Lu Q, Chaudry GJ, Leppla SH, Cohen SN (2006) The LDL receptorrelated protein LRP6 mediates internalization and lethality of anthrax toxin. Cell 124: 1141-1154.

9. Young JJ, Bromberg-White JL, Zylstra C, Church JT, Boguslawski E, et al. (2007) LRP5 and LRP6 are not required for protective antigen-mediated internalization or lethality of anthrax lethal toxin. PLoS Pathog 3: e27 doi:10.1371/journal.ppat.0030027.

10. Ryan PL, YoungJA (2008) Evidence against a human cell-specific role for LRP6 in anthrax toxin entry. PLoS ONE 3: el817.

11. Krantz BA, Melnyk RA, Zhang S, Juris SJ, Lacy DB, et al. (2005) A phenylalanine clamp catalyzes protein translocation through the anthrax toxin pore. Science 309: 777-781.

12. Rainey GJ, Wigelsworth DJ, Ryan PL, Scobie HM, Collier RJ, et al. (2005) Receptor-specific requirements for anthrax toxin delivery into cells. Proc Natl Acad Sci USA 102: 13278-13283.

13. Abrami L, Lindsay M, Parton RG, Leppla SH, van der Goot FG (2004) Membrane insertion of anthrax protective antigen and cytoplasmic delivery of may suppress their activity by preventing an essential step in T cell activation, that is CREB phosphorylation, and thereby allow the pathogen to escape the immune response. Further, a two-phase mechanism of action could contribute to explain the in vivo observation that the effects on $\mathrm{T}$ lymphocyte cytokine secretion change with the duration of EdTx intoxication [22]. This subversion mechanism of host cell functions, by untimely phosphorylation of CREB followed by inhibition of CREB activity, is likely to operate in other cell types besides $\mathrm{T}$ cells, as EdTx-mediated CREB phosphorylation was observed also in macrophages [64-66]. Moreover, this mechanism of action may be relevant to a number of bacterial toxins hitting upon host cell signaling, as suggested by the fact that not only EdTx but also CT is able to impair TCR-mediated CREB phosphorylation.

In conclusion, we identify PKA and CREB as targets of inhibition of $\mathrm{T}$ cell function caused by EdTx. Our data suggest that EdTx displays its action in two distinct phases: first, EdTx induces PKA-dependent CREB phosphorylation and expression of genes under the control of CRE; then, EdTx prevents CREB phosphorylation in response to incoming stimuli. This is a novel mode of intoxication by bacterial toxins acting on cellular signaling. Comparison of EdTx activity with that of other cAMP-elevating agents such as CT, CyaA and forskolin showed that EdTx is particularly efficient in affecting $\mathrm{T}$ cell function, probably owing to the duration and site of cAMP production.

\section{Acknowledgments}

We thank Manuela Zaccolo (Faculty of Biomedical Sciences, University of Glasgow, UK) for plasmids pcDNA3-RII-CFP and pcDNA3-C-YFP. A. P. wishes to thank David A. Cisneros for helpful discussions.

\section{Author Contributions}

Conceived and designed the experiments: AP CM. Performed the experiments: AP FDM SH. Analyzed the data: AP FDM SH. Contributed reagents/materials/analysis tools: DL CM. Wrote the paper: AP DL CM.

lethal factor occur at different stages of the endocytic pathway. J Cell Biol 166: 645-651.

14. Abrami L, Reig N, van der Goot FG (2005) Anthrax toxin: the long and winding road that leads to the kill. Trends Microbiol 13: 72-78.

15. Puhar A, Montecucco C (2007) Where and how do anthrax toxins exit endosomes to intoxicate host cells? Trends Microbiol 15: 477-482.

16. Dal Molin F, Tonello F, Ladant D, Zornetta I, Zamparo I, et al. (2006) Cell entry and cAMP imaging of anthrax edema toxin. EMBO J 25: 5405-5413.

17. Guidi-Rontani C, Weber-Levy M, Mock M, Cabiaux V (2000) Translocation of Bacillus anthracis lethal and oedema factors across endosome membranes. Cell Microbiol 2: 259-264.

18. Baldari CT, Tonello F, Paccani SR, Montecucco C (2006) Anthrax toxins: A paradigm of bacterial immune suppression. Trends Immunol 27: 434-440.

19. Turk BE (2007) Manipulation of host signalling pathways by anthrax toxins. Biochem J 402: 405-417.

20. Vitale G, Bernardi L, Napolitani G, Mock M, Montecucco C (2000) Susceptibility of mitogen-activated protein kinase kinase family members to proteolysis by anthrax lethal factor. Biochem J 352 Pt 3: 739-745.

21. Firoved AM, Miller GF, Moayeri M, Kakkar R, Shen Y, et al. (2005) Bacillus anthracis edema toxin causes extensive tissue lesions and rapid lethality in mice. Am J Pathol 167: 1309-1320.

22. Comer JE, Chopra AK, Peterson JW, Konig R (2005) Direct inhibition of T-lymphocyte activation by anthrax toxins in vivo. Infect Immun 73: 82758281

23. Fang H, Cordoba-Rodriguez R, Lankford CS, Frucht DM (2005) Anthrax lethal toxin blocks MAPK kinase-dependent IL-2 production in $\mathrm{CD}^{+} \mathrm{T}$ cells. J Immunol 174: 4966-4971.

24. Paccani SR, Tonello F, Ghittoni R, Natale M, Muraro L, et al. (2005) Anthrax toxins suppress $\mathrm{T}$ lymphocyte activation by disrupting antigen receptor signaling. J Exp Med 201: 325-331.

25. Rossi Paccani S, Tonello F, Patrussi L, Capitani N, Simonato M, et al. (2007) Anthrax toxins inhibit immune cell chemotaxis by perturbing chemokine receptor signalling. Cell Microbiol 9: 924-929. 
26. Lissandron V, Terrin A, Collini M, D'Alfonso L, Chirico G, et al. (2005) Improvement of a FRET-based indicator for cAMP by linker design and stabilization of donor-acceptor interaction. J Mol Biol 354: 546-555.

27. Tonello F, Naletto L, Romanello V, Dal Molin F, Montecucco C (2004) Tyrosine-728 and glutamic acid-735 are essential for the metalloproteolytic activity of the lethal factor of Bacillus anthracis. Biochem Biophys Res Commun 313: 496-502.

28. Karimova G, Fayolle C, Gmira S, Ullmann A, Leclerc C, et al. (1998) Chargedependent translocation of Bordetella pertussis adenylate cyclase toxin into eukaryotic cells: implication for the in vivo delivery of CD8(+) T cell epitopes into antigen-presenting cells. Proc Natl Acad Sci USA 95: 12532-12537.

29. Ausubel FM, Brent R, Kingston RE, Moore DD, Seidman JG, et al. (1999) Short Protocols in Molecular Biology. Fourth Edition ed: John Wiley \& Sons, Inc.

30. Abramoff MD, Magelhaes PJ, Ram SJ (2004) Image Processing with ImageJ. Biophotonics International 11: 36-42.

31. Laemmli UK (1970) Cleavage of structural proteins during the assembly of the head of bacteriophage T4. Nature 227: 680-685.

32. El-Azami-El-Idrissi M, Bauche C, Loucka J, Osicka R, Sebo P, et al. (2003) Interaction of Bordetella pertussis Adenylate Cyclase with CD11b/CD18: Role of Toxin Acylation and Identification of the Main Integrin Interaction Domain. J Biol Chem 278: 38514-38521.

33. Guermonprez P, Khelef N, Blouin E, Rieu P, Ricciardi-Castagnoli P, et al. (2001) The Adenylate Cyclase Toxin of Bordetella pertussis Binds to Target Cells via the $\{\{$ alpha $\}\}$ M $\{$ beta $\} 2$ Integrin (CD11b/CD18). J Exp Med 193: 1035-1044.

34. Lauer S, Goldstein B, Nolan RL, Nolan JP (2002) Analysis of Cholera ToxinGanglioside Interactions by Flow Cytometry. Biochemistry 41: 1742-1751.

35. Scobie HM, Thomas D, Marlett JM, Destito G, Wigelsworth DJ, et al. (2005) A soluble receptor decoy protects rats against anthrax lethal toxin challenge. J Infect Dis 192: 1047-1051.

36. Wigelsworth DJ, Krantz BA, Christensen KA, Lacy DB, Juris SJ, et al. (2004) Binding stoichiometry and kinetics of the interaction of a human anthrax toxin receptor, GMG2, with protective antigen. J Biol Chem 279: 23349-23356.

37. Shen Y, Zhukovskaya NL, Zimmer MI, Soelaiman S, Bergson P, et al. (2004) Selective inhibition of anthrax edema factor by adefovir, a drug for chronic hepatitis B virus infection. Proc Natl Acad Sci USA 101: 3242-3247.

38. Fimia GM, Sassone-Corsi P (2001) Cyclic AMP signalling. J Cell Sci 114: 1971-1972.

39. Johannessen M, Delghandi MP, Moens U (2004) What turns CREB on? Cell Signal 16: 1211-1227.

40. Johannessen M, Moens U (2007) Multisite phosphorylation of the cAMP response element-binding protein $(\mathrm{CREB})$ by a diversity of protein kinases. Front Biosci 12: 1814-1832.

41. Mayr B, Montminy M (2001) Transcriptional regulation by the phosphorylation-dependent factor CREB. Nat Rev Mol Cell Biol 2: 599-609.

42. Delghandi MP, Johannessen M, Moens U (2005) The cAMP signalling pathway activates CREB through PKA, p38 and MSK1 in NIH 3T3 cells. Cell Signal 17: 1343-1351.

43. Bos JL (2003) Epac: a new cAMP target and new avenues in cAMP research. Nat Rev Mol Cell Biol 4: 733-738.

44. HongJ, Doebele RC, Lingen MW, Quilliam LA, Tang WJ, et al. (2007) Anthrax edema toxin inhibits endothelial cell chemotaxis via Epac and Rapl. J Biol Chem 282: 19781-19787.

45. Davies SP, Reddy H, Caivano M, Cohen P (2000) Specificity and mechanism of action of some commonly used protein kinase inhibitors. Biochem J 351: 95-105.

46. Hughes-Fulford M, Sugano E, Schopper T, Li CF, Boonyaratanakornkit JB, et al. (2005) Early immune response and regulation of IL-2 receptor subunits. Cell Signal 17: 1111-1124.
47. Muthusamy N, Leiden JM (1998) A protein kinase C-, Ras-, and RSK2dependent signal transduction pathway activates the cAMP-responsive elementbinding protein transcription factor following $\mathrm{T}$ cell receptor engagement. J Biol Chem 273: 22841-22847.

48. Kaiser M, Wiggin GR, Lightfoot K, Arthur JS, Macdonald A (2007) MSK regulate TCR-induced CREB phosphorylation but not immediate early gene transcription. Eur J Immunol 37: 2583-2595.

49. Ogryzko VV, Schiltz RL, Russanova V, Howard BH, Nakatani Y (1996) The transcriptional coactivators p300 and CBP are histone acetyltransferases. Cell 87: 953-959.

50. Zhang X, Odom DT, Koo SH, Conkright MD, Canettieri G, et al. (2005) Genome-wide analysis of cAMP-response element binding protein occupancy, phosphorylation, and target gene activation in human tissues. Proc Natl Acad Sci USA 102: 4459-4464.

51. Abrahamsen H, Baillie G, Ngai J, Vang T, Nika K, et al. (2004) TCR- and CD28-mediated recruitment of phosphodiesterase 4 to lipid rafts potentiates TCR signaling. J Immunol 173: 4847-4858.

52. Kanda N, Watanabe S (2001) Regulatory roles of adenylate cyclase and cyclic nucleotide phosphodiesterases 1 and 4 in interleukin- 13 production by activated human T cells. Biochem Pharmacol 62: 495-507.

53. Dal Molin F, Zornetta I, Puhar A, Tonello F, Zaccolo M, et al. (2008) cAMP imaging of cells treated with pertussis toxin, cholera toxin, and anthrax edema toxin. Biochem Biophys Res Commun 376: 429-433.

54. Baillie GS, Houslay MD (2005) Arrestin times for compartmentalised cAMP signalling and phosphodiesterase-4 enzymes. Curr Opin Cell Biol 17: 129-134.

55. Cooper DM (2005) Compartmentalization of adenylate cyclase and cAMP signalling. Biochem Soc Trans 33: 1319-1322.

56. Wong W, Scott JD (2004) AKAP signalling complexes: focal points in space and time. Nat Rev Mol Cell Biol 5: 959-970.

57. Sayner S, Stevens T (2006) Soluble adenylate cyclase reveals the significance of compartmentalized cAMP on endothelial cell barrier function. Biochem Soc Trans 34: 492-494.

58. Sayner SL, Alexeyev M, Dessauer CW, Stevens T (2006) Soluble adenylyl cyclase reveals the significance of cAMP compartmentation on pulmonary microvascular endothelial cell barrier. Circ Res 98: 675-681.

59. Sayner SL, Frank DW, King J, Chen H, VandeWaa J, et al. (2004) Paradoxical cAMP-induced lung endothelial hyperpermeability revealed by Pseudomonas aeruginosa ExoY. Circ Res 95: 196-203.

60. del Carmen Castellanos M, Lopez-Giral S, Lopez-Cabrera M, de Landazuri MO (2002) Multiple cis-acting elements regulate the expression of the early $\mathrm{T}$ cell activation antigen CD69. Eur J Immunol 32: 3108-3117.

61. van Oirschot BA, Stahl M, Lens SM, Medema RH (2001) Protein kinase A regulates expression of $\mathrm{p} 27(\mathrm{kipl})$ and cyclin D3 to suppress proliferation of leukemic T cell lines. J Biol Chem 276: 33854-33860.

62. Fuld S, Borland G, Yarwood SJ (2005) Elevation of cyclic AMP in Jurkat T-cells provokes distinct transcriptional responses through the protein kinase A (PKA) and exchange protein activated by cyclic AMP (EPAC) pathways. Exp Cell Res 309: 161-173.

63. Tasken K, Stokka AJ (2006) The molecular machinery for cAMP-dependent immunomodulation in T-cells. Biochem Soc Trans 34: 476-479.

64. Maldonado-Arocho FJ, Fulcher JA, Lee B, Bradley KA (2006) Anthrax oedema toxin induces anthrax toxin receptor expression in monocyte-derived cells. Mol Microbiol 61: 324-337.

65. Park JM, Greten FR, Wong A, Westrick RJ, Arthur JS, et al. (2005) Signaling pathways and genes that inhibit pathogen-induced macrophage apoptosisCREB and NF-kappaB as key regulators. Immunity 23: 319-329.

66. Kim G, Wilcox-Adelman S, Sano Y, Tang WJ, Collier RJ, et al. (2008) Antiinflammatory cAMP signaling and cell migration genes co-opted by the anthrax bacillus. Proc Natl Acad Sci USA 105: 6150-6155. 